\title{
Pain changes and new neurologic sign in post-herpetic neuralgia: a clue in the diagnosis of malignancy-a case report
}

\author{
Sung Hyun Lee ${ }^{1 \#}$, Jin Young Lee ${ }^{2 \#}$, Hyojin Yeon ${ }^{3}$, Min Cheol Rho ${ }^{3}$, Jinhoon Bae ${ }^{3}$, Hue Jung Park ${ }^{3 \wedge}$ \\ ${ }^{1}$ Department of Anesthesiology and Pain Medicine, Kangbuk Samsung Hospital, Sungkyunkwan University School of Medicine, Seoul, Republic \\ of Korea; ${ }^{2}$ Department of Anesthesiology and Pain Medicine, Samsung Medical Center, Sungkyunkwan University, School of Medicine, Seoul, \\ Republic of Korea; ${ }^{3}$ Department of Anesthesiology and Pain Medicine, Seoul St. Mary's Hospital, College of Medicine, The Catholic University of \\ Korea, Seoul, Republic of Korea \\ Contributions: (I) Conception and design: SH Lee, HJ Park; (II) Administrative support: JY Lee, HJ Park; (III) Provision of study materials or patients: \\ H Yeon; (IV) Collection and assembly of data: MC Rho, J Bae; (V) Data analysis and interpretation: HJ Park, SH Lee, JY Lee; (VI) Manuscript \\ writing: All authors; (VII) Final approval of manuscript: All authors. \\ \#These authors contributed equally to this work. \\ Correspondence to: Hue Jung Park, MD, PhD. Department of Anesthesiology and Pain Medicine, Seoul St. Mary's Hospital, College of Medicine, The \\ Catholic University of Korea, 222 Banpo-daero, Seocho-gu, Seoul, 06591, Republic of Korea. Email: huejung@catholic.ac.kr.
}

\begin{abstract}
Herpes zoster (HZ) results from the reactivation of latent varicella-zoster virus in the dorsal root ganglion neurons. The most common complication of $\mathrm{HZ}$ is post-herpetic neuralgia (PHN), characterized by persisting neuropathic pain in the affected dermatome after the rash recedes. The immune system is more compromised in older people, which leads to an increase in the incidence of HZ and PHN. Several studies have revealed that $\mathrm{HZ}$ or PHN is associated with an increased risk of malignancy in immune-suppressed patients. An 83-year-old man visited our pain clinic with facial pain 6 months after he was diagnosed with recurred $\mathrm{HZ}$ on the right V1 dermatome. He was diagnosed with $\mathrm{HZ}$ on the right $\mathrm{C} 2$ dermatome 5 years ago. He could not perform a right lateral gaze for the past 3 months. Moreover, the symptoms did not improve and the pain was aggravated on the face and head. We considered two possibilities: HZ affecting motor neuron and occult malignancy. Brain magnetic resonance imaging and magnetic resonance angiography showed a mass lesion that should have been differentiated, and his blood was positive for prostate specific antigen. The probability of occult malignancy should be taken into account in elderly patients with $\mathrm{HZ}$ or PHN.
\end{abstract}

Keywords: Abducens nerve palsy; case report; herpes zoster (HZ); malignancy; post herpetic neuralgia (PHN)

Submitted Oct 13, 2021. Accepted for publication Dec 24, 2021.

doi: $10.21037 / \mathrm{apm}-21-2567$

View this article at: https://dx.doi.org/10.21037/apm-21-2567

\section{Introduction}

Herpes zoster (HZ) results from the reactivation of latent varicella-zoster virus (VZV) in the dorsal root ganglion neurons. The incidence and prevalence of $\mathrm{HZ}$ increase with age. The most common complication of $\mathrm{HZ}$ is post-herpetic neuralgia (PHN), characterized by persisting neuropathic pain in the affected dermatome after the rash recedes. Old age is one of risk factor of PHN (1). The immune system is more compromised in older people, which leads to an increase in the incidence of HZ and PHN (2). Several studies have revealed that $\mathrm{HZ}$ or PHN is associated with an increased risk of malignancy in immune-suppressed patients (3). It has also been demonstrated that $\mathrm{HZ}$ develops more frequently in patients with a preceding malignancy (4).

$\wedge$ ORCID: 0000-0002-3775-1794. 

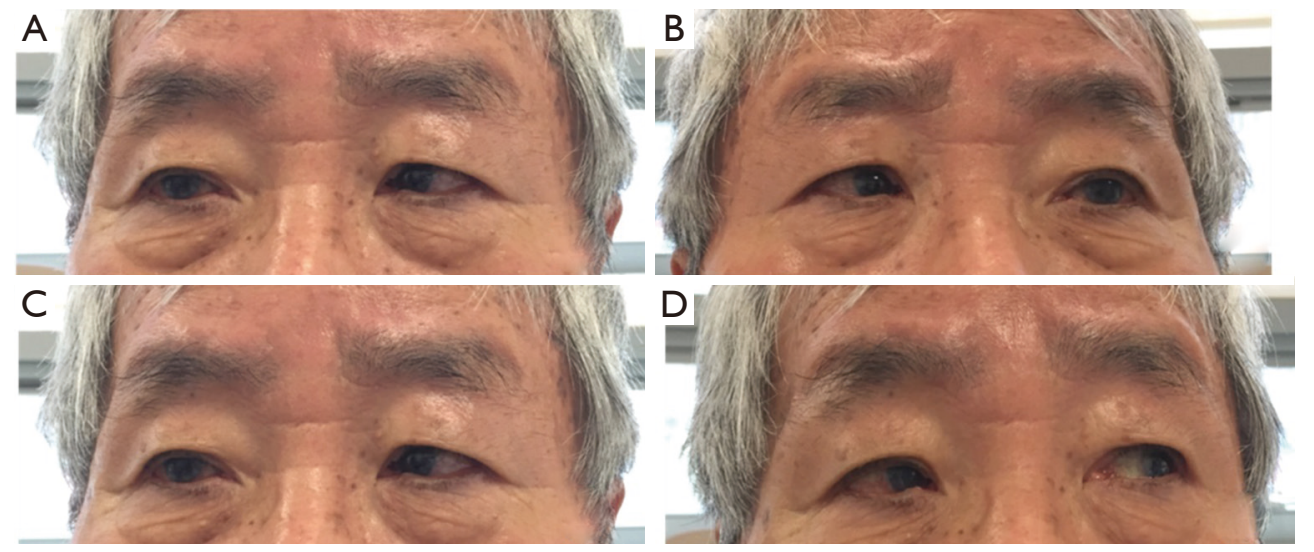

Figure 1 The patient could not perform right lateral gaze. The eye movements on all other sides except lateral gazing were intact. He cannot see right upper (A) and lower (C) lateral side. However, he can see left upper (B) and lower (D) lateral side. The images are published with the patient's consent.

Moreover, some studies suggest that $\mathrm{HZ}$ is a marker of occult or subsequent cancer $(5,6)$. When physicians treat elderly patients with $\mathrm{HZ}$ or PHN, they should bear in mind the possibility of malignancy. Especially, when a patient with PHN complains of a change in the nature of the pain from the previous pain or of new neurologic symptoms, an occult malignancy should be considered (7). We present the following case in accordance with the CARE reporting checklist (available at https://apm.amegroups.com/article/ view/10.21037/apm-21-2567/rc).

\section{Case presentation}

The study was approved by the Institutional Review Board of Seoul St. Mary's Hospital (No. KC16ZISE0090). All procedures performed in this study were in accordance with the ethical standards of the institutional and/or national research committee(s) and with the Helsinki Declaration (as revised in 2013). Written informed consent was obtained from the patient for publication of this case report and accompanying images. A copy of the written consent is available for review by the editorial office of this journal. An 83 -year-old male patient visited our pain center complaining of facial pain and headache. He had no present illness and got a cataract surgery 8 years ago. He was diagnosed with $\mathrm{HZ}$ on the right $\mathrm{C} 2$ dermatome 5 years ago. Skin rash had spread to areas behind the right ear and to the right-side of the neck. At that time, he was treated with an antiviral agent and analgesic agents at a local dermatology clinic. However, he did not remember the exact name of drugs or ingredients. The rash and pain disappeared. HZ reappeared on the different region of the face, on eye brow, forehead, and right eye 6 months ago on the right V1 dermatome. Although, he was treated with the same medication, he continued to suffer pain. He was prescribed gabapentin $300 \mathrm{mg}$ tid by a neurologist for 6 months. He also visited an ophthalmic center due to diplopia. In the last 3 months, the symptoms did not improve and the pain was aggravated on the face and head. The ophthalmologist referred the patient to our pain center. He could not perform a right lateral gaze, which corresponded to the sixth nerve (abducens nerve) palsy (Figure 1). After detailed interview with the patient, we recognized that the nature of the pain had changed. Three months ago, the pain was limited to the right side of his head, but now the headache was vague on the right side. The location of the pain around the eye had not changed; however, the intensity was higher. We considered two possibilities: $\mathrm{HZ}$ affecting motor neuron and occult malignancy. We checked VZV IgM, IgG, and tumor markers in the blood, brain magnetic resonance imaging (MRI), and magnetic resonance angiography (MRA). Supraorbital nerve block, infraorbital nerve block, and occipital nerve block using $0.4 \%$ lidocaine $2 \mathrm{~mL}$ each site under ultrasound-guide were done to relieve his pain. After 2 weeks, the patient revisited our pain center. His facial pain had improved but his headache still persisted. VZV IgG was positive and VZV IgM was negative; however, prostate specific antigen (PSA) was positive $(10.22 \mathrm{ng} / \mathrm{dL})$. Brain MRI and MRA showed a $15 \mathrm{~mm} \times 28 \mathrm{~mm}$ sized mass in the right Meckel's cave, infiltrative enhancing lesion 

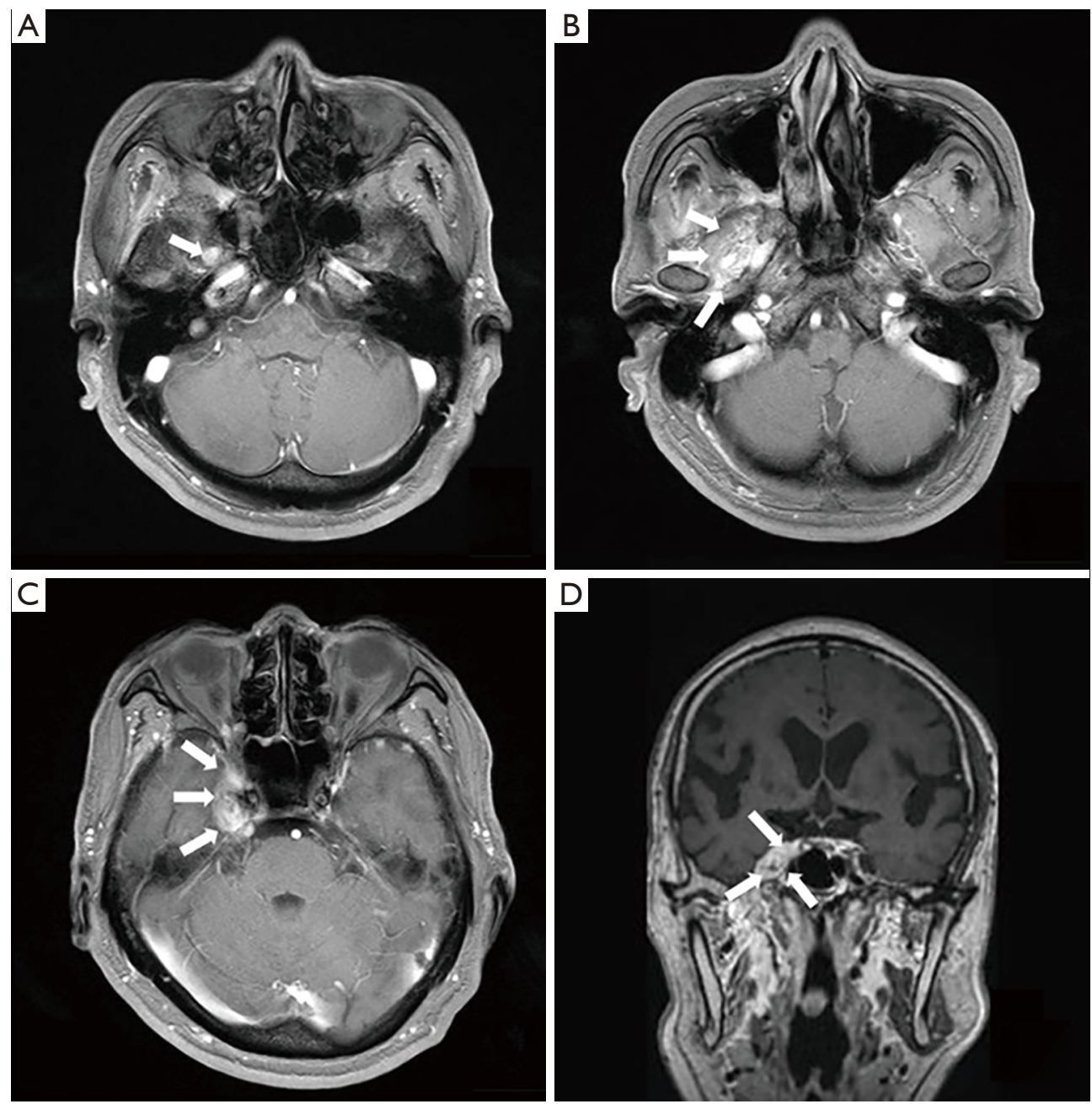

Figure 2 Brain MRI and MRA of the patient show a infiltrative enhancing lesion involving right Meckel's cave, foramen ovale-infratemporal fossa, vidian canal, foramen rotundum, pterygopalatine fossa, inferior orbital fissure and orbital apex (arrows). Main mass is located in right Meckel's cave $(15 \mathrm{~mm} \times 28 \mathrm{~mm}$ ) with small portion protruding into prepontine cistern. (A-C) Axial scan, (D) coronal scan. MRI, magnetic resonance imaging; MRA, magnetic resonance angiography.

involving foramen ovale-infratemporal fossa, vidian canal, foramen rotundum, pterygopalatine fossa, inferior orbital fissure and orbital apex, which needed differential diagnosis of neurogenic tumor and of metastasis (Figure 2). His symptoms may be caused by malignancy rather than the recurrence of $\mathrm{HZ}$ on the sixth cranial nerve. We referred him to Neurosurgery department for further evaluation and treatment. A neurosurgeon recommended him to get a tumor resection or biopsy. But, he refused any surgery and just wanted conservative treatment because of his old age. After 2 years, due to hydrocephalus, he got surgery two times (endoscopic 3rd ventriculostomy and VentriculoPeritoneal Shunt, September and October in 2017, respectively). Nowadays, he receives conservative treatment.

\section{Discussion}

This case report shows that malignancy was diagnosed through the clues of motor palsy and change of the nature of the pain in an elderly patient with PHN. For several years, many well designed studies have revealed that not only $\mathrm{HZ}$ occurs more frequently in patients with cancer, but also HZ-related complications like PHN occurs more frequently in them (8). A study of 14,670 patients with cancer showed a 4.8 times higher incidence rate of $\mathrm{HZ}$ in patients with hematologic malignancies and 1.9 times 
higher incidence rate in those with solid tumors compared to a general population (9). Old age ( $>65$ years) is a risk factor of HZ. A retrospective, cohort study with an initial sample of 2,110,735 cancer and 676,712 non-cancer patients documented a higher risk of $\mathrm{HZ}$ in elderly patients with cancer than in patients with only one risk factor, old age ( $>65$ years) or cancer (10). This study also showed that the median time of $\mathrm{HZ}$ onset after cancer diagnosis was 34.0 months. Some studies suggested that HZ might be a marker of occult or subsequent cancer (11). A study of 542,575 individuals documented that the incidence of cancer was significantly greater among individuals with $\mathrm{HZ}$ than among those without HZ (12). This study shows that the risk is greatest during the first 180 days after the diagnosis of HZ (12). The possible mechanisms for $\mathrm{HZ}$ preceding the manifestation of cancer were suggested to be associated with the immune system. Some cancers developed at the pre-clinical and prodromal stage when the immune system was impaired. HZ could be an early manifestation of the defect in the immune system provoked by the cancer. Both reactivation of $\mathrm{HZ}$ and immunological monitoring against malignancy are associated with cellular immunity (CD4+ $\mathrm{T}$ cells and natural killer cells) (5). Any dysfunction of the immune system can result in the expression of both HZ and malignancy. Hence, when a clinician treats an elderly patient with HZ, the possibility of malignancy should be considered. Change in the nature of the pain or newly developed neurologic signs should not be ignored.

\section{Acknowledgments}

Funding: None.

\section{Footnote}

Reporting Checklist: The authors have completed the CARE reporting checklist. Available at https://apm.amegroups. com/article/view/10.21037/apm-21-2567/rc

Conflicts of Interest: All authors have completed the ICMJE uniform disclosure form (available at https://apm. amegroups.com/article/view/10.21037/apm-21-2567/coif). The authors have no conflicts of interest to declare.

Ethical Statement: The authors are accountable for all aspects of the work in ensuring that questions related to the accuracy or integrity of any part of the work are appropriately investigated and resolved. The study was approved by the Institutional Review Board of Seoul St. Mary's Hospital (No. KC16ZISE0090). All procedures performed in this study were in accordance with the ethical standards of the institutional and/or national research committee(s) and with the Helsinki Declaration (as revised in 2013). Written informed consent was obtained from the patient for publication of this case report and accompanying images. A copy of the written consent is available for review by the editorial office of this journal.

Open Access Statement: This is an Open Access article distributed in accordance with the Creative Commons Attribution-NonCommercial-NoDerivs 4.0 International License (CC BY-NC-ND 4.0), which permits the noncommercial replication and distribution of the article with the strict proviso that no changes or edits are made and the original work is properly cited (including links to both the formal publication through the relevant DOI and the license). See: https://creativecommons.org/licenses/by-nc-nd/4.0/.

\section{References}

1. Jeon YH. Herpes Zoster and Postherpetic Neuralgia: Practical Consideration for Prevention and Treatment. Korean J Pain 2015;28:177-84.

2. Christo PJ, Hobelmann G, Maine DN. Post-herpetic neuralgia in older adults: evidence-based approaches to clinical management. Drugs Aging 2007;24:1-19.

3. McKay SL, Guo A, Pergam SA, et al. Herpes Zoster Risk in Immunocompromised Adults in the United States: A Systematic Review. Clin Infect Dis 2020;71:e125-34.

4. Tran TN, Ray GT, Horberg MA, et al. Complications of herpes zoster in cancer patients. Scand J Infect Dis 2014;46:528-32.

5. Buntinx F, Wachana R, Bartholomeeusen S, et al. Is herpes zoster a marker for occult or subsequent malignancy? $\mathrm{Br} \mathrm{J}$ Gen Pract 2005;55:102-7.

6. Chiu HF, Chen BK, Yang CY. Herpes zoster and subsequent risk of cancer: a population-based study. J Epidemiol 2013;23:205-10.

7. Lojeski E, Stevens RA. Postherpetic neuralgia in the cancer patient. Curr Rev Pain 2000;4:219-26.

8. Onozawa M, Hashino S, Haseyama $Y$, et al. Incidence and risk of postherpetic neuralgia after varicella zoster virus infection in hematopoietic cell transplantation recipients: Hokkaido Hematology Study Group. Biol Blood Marrow Transplant 2009;15:724-9.

9. Habel LA, Ray GT, Silverberg MJ, et al. The epidemiology 
of herpes zoster in patients with newly diagnosed cancer. Cancer Epidemiol Biomarkers Prev 2013;22:82-90.

10. Yenikomshian MA, Guignard AP, Haguinet F, et al. The epidemiology of herpes zoster and its complications in Medicare cancer patients. BMC Infect Dis 2015;15:106.

Cite this article as: Lee SH, Lee JY, Yeon H, Rho MC, Bae J, Park HJ. Pain changes and new neurologic sign in post-herpetic neuralgia: a clue in the diagnosis of malignancy - a case report. Ann Palliat Med 2022;11(8):2773-2777. doi: 10.21037/apm-21-2567
11. Jung HS, Kang JK, Yoo SH. Epidemiological Study on the Incidence of Herpes Zoster in Nearby Cheonan. Korean J Pain 2015;28:193-7.

12. Iglar K, Kopp A, Glazier RH. Herpes zoster as a marker of underlying malignancy. Open Med 2013;7:e68-73. 